\title{
Análise do Parágrafo 16 do L. VII das Confissões, de Santo Agostinho
}

Cléver Cardoso

\section{Resumo:}

Pretendemos analisar o décimo sexto parágrafo do L. VII das Confissões, de Santo Agostinho, tomando como principal mote de análise a noção de espaço local nele contida. Sendo assim, nosso trabalho se engendrará por explicar como o parágrafo I6 se caracteriza como o clímax do L. VII, sendo que ele é o momento central para o abandono da exterioridade em direção de uma interiorização nas Confissões.

Palavras-chave: Agostinho, Confissões, espaço local, interiorização. 


\section{Introdução}

O presente artigo tem como objetivo primeiro um estudo detalhado sobre o décimo sexto parágrafo do L. VII das Confissões, de Santo Agostinho. Esse estudo atentará principalmente para a expressão locorum spatia inscrita nesse trecho do texto agostiniano. Mas com qual justificativa pode se atentar para essa expressão em especial dentro não só desse parágrafo como também da obra confessional de Agostinho?

Antes de responder essa questão primeira, é necessário localizar o parágrafo dezesseis dentro do L. VII. Pode-se considerar esse livro como um esforço agostiniano em ver. Ele se engendra, no decorrer das Confissões, como um esforço do Bispo de Hipona em ver aquilo que ele apenas concebia. Ou seja, Agostinho era capaz de conceber algumas noções, mas não de ver suas causas. Sendo assim, Agostinho procura, no decorrer do L. VII, depurar sua visão para enxergar a Verdade. De tal modo, o Bispo trata primeiramente de mostrar como concebia erroneamente Deus como um ser corpóreo e inserido no espaço; posteriormente, como concebia a incorruptibilidade de Deus, mas não conseguia engendrar essa incorruptibilidade com o problema da existência do mal; adiante, Agostinho faz uma refutação a astrologia, criticando seu racionalismo determinista do cosmos; e, enfim, começa a narrar o socorro divino operando em sua vida, através da leitura dos neoplatônicos, culminando no momento central do livro - o parágrafo dezesseis - no qual o Bispo vê a verdade e, a partir daí, pode destrinchar a resolução dos problemas apresentados anteriormente. Se se aceitar essa centralidade do parágrafo dezesseis no interior do L. VII, podemos explicálo como o êxtase do esforço da visão. Esse êxtase é dado por um lento processo narrado nos parágrafos anteriores em que Agostinho quer se desvencilhar da visão corporal para ver com a alma. Esse lento processo é marcado por uma crítica de concepções espacializantes.

Ora, mas como o L. VII pode ter essa crítica de concepções espacializantes em vista da depuração da visão como primazia? Para responder essa questão, adotar-se-á, como estratégia, a constatação do vocabulário empregado por Agostinho nesse livro. É nele em que aparecem pela primeira vez em grande número as expressões advindas da palavra spatium. No entanto, a aparição dessas expressões em livros anteriores também nos apontam um fator relevante. Excluída a primeira aparição no L. I, a qual, apesar de engendrada no esqueleto argumentativo agostiniano, sua análise fugiria do escopo que aqui se pretende delimitar, as outras três aparições parecem remeter diretamente ao L. VII. A primeira delas está presente no L. III e é dada por: 
E não sabia que Deus é espírito, que não tem membros em comprimento e largura, que não tem matéria, porque a matéria é menor na parte que no todo, e, se for infinita, é menor numa parte delimitada por um espaço [spatio] definido do que pelo infinito, e não está em toda parte, tal como o espírito, tal como Deus (AGOSTINHO, 2004, p.IO3).

É nesse livro que Agostinho conta sua adesão ao maniqueísmo e nesse trecho ele narra que ainda não sabia a falsidade dessa doutrina. A relação do conteúdo supracitado com o L. VII é evidente. É neste que Agostinho refuta por completo, após a visão êxtásica do parágrafo dezesseis, as teses maniquéias, tal qual a da concepção de Deus como um ser corpóreo e inserido no espaço. Mas que se veja a segunda das aparições escolhidas, ela se encontra no seguinte trecho do L. $\mathrm{V}:$

Parecia melhor crer que tu não criaste nenhum mal - mal que, na minha ignorância, não só se me afigurava uma substância, mas também uma substância corpórea, porque não era capaz de conceber que a mente pensasse ela própria se a mente não fosse um corpo subtil, que, no entanto, se difunde pelos espaços [spatia] - antes isso do que crer que de ti derivava a natureza do mal como eu a concebia. (Ibid, p. 203)

Nesse trecho, pode-se notar que Agostinho narra seu erro em relação à concepção de mal que possuía, tal que essa concepção também se prende a uma espacialização. Concepção essa que também será refutada no L. VII como já dito anteriormente. Resta, então, a última aparição a ser citada, integrante do L. VI:

E assim me envergonhava e arrependia, e me alegrava, meu Deus, porque a tua Igreja, única, corpo do teu Filho único, na qual me foi inculcado em criança o nome de Cristo, não apreciava esses diparates infantis, nem tinha na sua sã doutrina nada que te empurrasse, a ti, criador de todas as coisas, para um espaço [spatium], embora sublime e amplo, todavia limitado por todos os lados pela figura dos membros humanos. (Ibid, p.225)

Narrando seu contato com Ambrósio e a falsidade das acusações e dos argumentos maniqueus contra os católicos, Agostinho mostra, mais uma vez, como concebia Deus de maneira corpórea. Concepção essa que Agostinho revela, num momento logo anterior ao último trecho supracitado, ser uma falsidade que foi negada mais tarde a esse episódio de sua vida. Esse momento mais tarde, segundo o que se pretende defender neste artigo, é o L. VII. 
Dessa maneira, a resposta a nossa questão primeira pode ser dada: uma análise do parágrafo dezesseis exige a consideração da crítica da espacialidade, pois é essa crítica que permite não só a refutação das teses maniquéias, como também a própria visão da Verdade com os olhos da mente, em detrimento dos olhos do corpo. A escolha vocabular do L. VII expressa essa crítica das noções espaciais e, para além dele, os vocábulos espaciais anteriores a esse livro apontam para as refutações aos maniqueus elaboradas no mesmo.

Acredita-se, então, ter delimitado a justificativa de uma análise do parágrafo dezesseis como de grande relevância dentro da obra confessional, tendo em vista seu prenúncio nas aparições dos vocábulos espacializantes nos livros precedentes; e como momento central do L. VII, já que nele é dado o clímax da visão da Verdade que depende da crítica do espaço local. Por isso, a análise desse parágrafo privilegiando a atenção para expressão locorum spatia se faz delimitada dentro das Confissões e, em específico, do L. VII.

Mas antes de se passar à análise do texto agostiniano, é importante anunciar como se procederá essa análise. Primeiramente, é relevante o anúncio das obras a serem consultadas:

- Bíblia de Jerusalém

- Bíblia do Peregrino

- Confissóes

- Comentário aos Salmos

A escolha desses textos se deu por conta da referência no parágrafo dezesseis a alguns trechos bíblicos e, entre eles, alguns Salmos. Tal que a leitura desses trechos no original bíblico se mostrará importante para a compreensão e explanação do texto Agostiniano. Sendo assim, por conta das referências sálmicas, o Enarrationes do Bispo de Hipona ajudará o entendimento dessas passagens, reforçando a compreensão do trecho a ser analisado.

Destarte, finda-se a delimitação deste estudo e a maneira como ele procederá. Então, que se passe à execução do que, até agora, foi somente apresentado.

\section{Análise}

O parágrafo dezesseis do L. VII se inicia com o seguinte trecho: "E, admoestado a voltar daí para mim mesmo, entrei no mais íntimo de mim, guiado por ti, e consegui, porque te fizeste meu auxílio.” (Ibid, p. 295) Esse primeiro trecho a ser analisado já mostra uma primeira dualidade que adiantou-se anteriormente. Ela trata da relação entre interioridade e exterioridade, ou como se poderá dizer 
posteriormente: visão da alma e visão corporal. Nesse excerto, é interessante notar que Agostinho foi admoestado, isto é, ele foi impelido a voltar para si mesmo. Mas voltar de onde? Se se pensar naquilo que foi dito anteriormente na introdução deste estudo, seria possível dizer que o bispo volta das falsas doutrinas maniquéias espacializantes para o seu interior. No escopo geral do pensamento agostiniano, uma afirmação como essa não estaria errada. No entanto afirmá-la nesse momento como explicação da volta referida pelo autor seria cometer um pequeno deslize. Agostinho volta da leitura dos neoplatônicos (parágrafos treze a quinze do L. VII) para seu interior, tal que a admoestação provocadora da volta é, por um lado, a da conversão intelectual através da leitura desses textos e, por outro, a da graça de Deus que opera na vida do filósofo, fazendo com que este volte para seu íntimo. Mas por que Deus admoesta Agostinho a sair da leitura dos platônicos e voltar para seu íntimo? Para responder a essa questão, é notório o seguinte trecho do parágrafo catorze:

Mas aqueles que, ensoberbecidos, levantados no coturno como que de uma doutrina mais sublime, não o ouvem dizer: Aprendei de mim, porque sou manso e humilde de coração, e encontrareis repouso para as vossas almas, embora conheçam Deus, não o glorificam como Deus ou lhe dão graças, mas tornam-se vãos nos seus pensamentos, e o seu coracão, insensato, obscurece-se; dizendo que são sábios, tornaram-se estultos. (Ibid, p. 293)

Os neoplatônicos conhecem Deus, no entanto não o louvam, não reconhecem a autoridade das Escrituras, não se fazem humildes e perdem-se na soberba. Por isso, além de haver uma admoestação intelectual através da leitura desses mesmos platônicos que faz Agostinho abandonar a exterioridade para entrar no seu íntimo, há também uma admoestação divina que faz Agostinho sair da leitura desses textos em direção a sua interioridade. No entanto, se um passo atrás for dado e olharmos para a admoestação num plano mais geral, pode-se dizer que as duas admoestações são divinas. A leitura dos textos neoplatônicos também é obra da graça divina e, além disso, a progressão ali atingida no conhecimento, isto é, o abandono da exterioridade também só foi possível por conta da iluminação divina. Desse modo, o motivo de Agostinho abandonar a leitura dos neoplatônicos é que eles, apesar de atingirem um certo grau de conhecimento que permite o abandono da exterioridade, não aceitam que esse conhecimento é proveniente da iluminação divina e, por isso, perdem-se na soberba. Portanto, não há duas admoestações, mas uma só, a divina, que opera no abandono da exterioridade em direção da interioridade, mas fazendo alerta que o mesmo caminho intelectual percorrido pelos neoplatônicos foi incompleto. Sendo assim, faz-se necessário 
dizer que Deus é guia e auxílio e a presença da alusão ao Salmo 29 no fim deste trecho não é sem propósito. No Comentário aos Salmos, Agostinho comenta os versículos anteriores ao citado nesse trecho das Confissões dizendo:

$\mathrm{Na}$ terra, onde agora se acha [o homem] clame e diga: 'Senhor, por ti clamarei e suplicarei a meu Deus'. No paraíso não clamavas, mas louvava; não gemias, mas fruías. Fora dele geme e clama. O Senhor, que abandonou o soberbo, aproxima-se do atribulado, porquanto 'Deus resiste aos soberbos; mas dá graça aos humildes.' ( $\operatorname{Tg} 4,6)$. Porventura o pó te há de louvar? Ou enaltecer a tua verdade?' Duas são as espécies de confissão: a do pecado e a de louvor. Se vamos mal, confessemos nossos pecados, no meio de nossas tribulações; se vamos bem, com exultação da justiça confessemos, em louvar a Deus. Todavia, jamais fiquemos sem confissão. (AGOSTINHO, I998, p.292)

Pode-se ver claramente o que está dito: Deus dá graça aos humildes, em detrimento dos soberbos, e, se esses recebedores da graça vão bem, devem louvar a Deus. Ora, o conhecimento da negação da exterioridade é um bem e, por isso, os platônicos deveriam louvar a Deus. No entanto, estes não louvam e afastamse de Deus por conta de sua soberba. Para não se afastar ainda mais de Deus, Agostinho confessa tanto seus pecados quanto a primazia de Deus em qualquer conhecimento atingido. A interiorização só é possível por conta da iluminação divina e ação da graça de Deus, tal que isso deve ser professado pelo filósofo: o louvor é obrigatório.

Uma vez dentro de si, o que Agostinho vê? "Entrei e vi com o olhar da minha alma, acima [supra] da minha mente, uma luz imutável, não esta vulgar e visível a toda a carne, nem era uma maior como que do mesmo gênero, como se ela brilhasse muito e muito mais claramente e ocupasse tudo com a sua grandeza." (AGOSTINHO, 2004, p.295) Não é de assustar que Agostinho veja uma luz. A mesma luz que ilumina sua alma para que ele tenha chegado até seu íntimo. Mas como é essa luz? A única afirmação que o autor nos dá a respeito dela é que é imutável, sendo que todas as proposições seguintes são veementemente negativas. Agostinho dirá o que essa luz não é. Primeiramente, ela não é a luz que se vê com a visão corporal da carne, a luz que ocupa o espaço. Se fosse tal luz, teria que se admitir que esta fosse infinita e onipresente, no entanto, como exposto nos primeiros parágrafos do L. VII, uma noção espacializante da luz divina leva à concepção de que ela, enquanto espacial, deve estar em todos os espaços, logo um espaço maior conteria mais dessa luz que um menor. Mas acreditar nesse tese leva a acreditar que Deus é corruptível, pois ele teria que estar presente 
nos espaços das coisas corruptíveis do mundo. Sendo assim, outro problema é colocado: se se acreditar nessa tese, ter-se-á que acreditar que Deus está presente em coisas más. O problema da existência do mal é, então, engendrado. Essa tese da concepção corporal de Deus, advinda da filiação de Agostinho ao pensamento maniqueu, ainda não foi refutada, porém é a visão que Agostinho tem no parágrafo dezesseis que permitirá sua refutação. Mas como essa luz está acima da mente de Agostinho? A dificuldade em expressar o caráter de estar supra mentem mea se dá justamente por supra nos remeter diretamente à espacialidade. Com isso, Agostinho prossegue: "Ela não era isto, mas outra coisa, outra coisa muito diferente de todas essas, nem tão-pouco estava acima [super] da minha mente como o azeite sobre a água, nem como o céu sobre a terra, mas era superior [superior] a mim, porque ela própria me fez, e eu inferior, porque feito por ela." (Ibid.) A luz vista não é a espacial e, além disso, ela não está acima da mente do filósofo no sentido espacial ${ }^{1}$. Essa superioridade não é a das metáforas corporais do azeite sobre a água ou do céu sobre a terra, ela é uma superioridade ontológica. Deus é superior porque ele é o Ser e dá ser às criaturas, ou seja, Deus é superior, porque é Criador. Portanto, fica assentado ao fim dessas negativas que essa luz não é espacial e não está espacialmente acima da mente do filósofo.

Não obstante, apesar de se saber o que essa luz não é (e tal conhecimento não é simples), o que é essa luz? O Bispo prossegue: "Quem conhece a verdade, conhece-a, e quem a conhece, conhece a eternidade. O amor conhece-a." (Ibid.) Essa luz é a verdade e a eternidade. É extremamente relevante o fato da crítica das noções espacializantes da luz permitir dizer que ela é eterna. Agostinho ainda não sabe o que é essa eternidade, no entanto, ele pode, nesse momento, vê-la. A relevância se dá porque o momento de esforço para saber o que é a eternidade se dará no L. XI das Confissões e lá Agostinho fará, assim como aqui, uma depuração, pelo menos num primeiro momento, de noções espacializantes não da luz divina, mas do tempo. Desse modo, se aqui a crítica das concepções espacializantes da luz divina permitem a visão dessa luz eterna, no L. XI o esforço empreendido será por uma crítica das concepções espacializantes do tempo - que engendrará outros problemas - em busca não mais de uma mera visão da eternidade, mas da

I O dicionário Oxford de Latim coloca, além dos significados de supra e superior que remetem à espacialidade, um que se notou relevante: o de anterioridade numa sequência causal. No entanto, no verbete super não há tal significado. Por não haver certeza sobre o significado dos verbetes, preferiu-se indicar tal constatação em nota de rodapé. Contudo, é interessante notar que Agostinho usa supra e superior para remeter à luz imutável que ele acabara de ver, enquanto usa super para remeter à superioridade espacial das metáforas corporais. Dentro do projeto da filosofia Agostiniana, faz sentido pensar na superioridade divina enquanto precedência numa seqüência causal, já que Deus é o Criador. 
compreensão do que ela é. Nesse espectro, o prosseguimento do texto pode ser interessante para se entender tal constatação: "Oh, eterna verdade e verdadeiro amor e amorosa eternidade!" (Ibid.) Agostinho sobrepõe a verdade, o amor e a eternidade, de modo que a visão da luz imutável, verdadeira e eterna pelo amor se mostra insuficiente. A crítica à espacialidade dada no decorrer do L. VII e a visão da verdade permitem o abandono e negação das teses maniquéias, no entanto ver não é saber e o Bispo não sabe o que é essa luz, já que ele não sabe o que é a eternidade. Se a luz é verdade e a verdade é eternidade, o conhecimento do que ela é é um problema cuja tentativa de resolução se dará somente no L. XI, onde haverá uma depuração de concepções espacializantes do tempo que apontará para uma crítica das concepções temporalizantes da eternidade.

Agostinho prossegue: "Tu és o meu Deus, por ti suspiro dia e noite" (Ibid.) Nesse trecho, há duas alusões sálmicas. A primeira delas se refere ao Salmo 42, no qual estão os versículos 2 e 3: "Sim, tu é o meu Deus forte: / por que me rejeitas? Por que devo andar pesaroso / pela opressão do inimigo? Envia tua luz e tua verdade: / elas me guiarão / levando-me à tua montanha sagrada, às tuas Moradias." (AGOSTINHO, 2008) No Enarrationes (AGOSTINHO, 2004, P.7I4), o Bispo comenta a seguinte passagem dizendo que Deus é a fortaleza, e não sua alma. Além disso, o autor diz que a luz de Deus é a Verdade de Deus e ambas são dois nomes para uma só realidade. A luz e a Verdade são os guias mestres que iluminam os olhos do coração e conduzem a alma ao monte santo, que é a Igreja. Desse modo, a luz imutável vista pela alma de Agostinho é a Verdade de Deus e essa Verdade não pode ser considerada como fruto da alma do homem. Ela é proveniente apenas de Deus e ilumina o coração do homem. Esse coração, que alguns poderiam confundir com o amor, é, na verdade, o espírito do homem, a sede de sua racionalidade. Tal que a luz está pautada na fortaleza divina e ilumina a razão humana, por isso o filósofo deve louvá-la. Esse louvor é justificado na segunda alusão sálmica, que remete ao primeiro Salmo bíblico: "Pelo contrário: / seu prazer está na lei de Iahweh, / e medita sua lei dia e noite." (AGOSTINHO, 2008) No Comentário aos Salmos, Agostinho argumenta que a lei a qual esse Salmo se refere é a lei apreendida pelo intelecto e ela é meditada tanto na tribulação (noite) quanto na alegria (dia). Desse modo, meditar a lei é confessar a proveniência da luz imutável de Deus, confissão essa que é tanto do pecado (tribulações), quanto do louvor (alegria). Se se vê essa luz, deve-se confessar, por um lado, a insuficiência humana em relação à mesma, por outro, a misericórida divina por possibilitar que ela seja vista. Portanto, a confissão de pecado e de louvor deve se engendrar no propósito humilde das Confissões, conflitando com a soberba dos que arrogam para si a visão da Verdade. 
O filósofo continua: "E logo que te conheci, tu arrebataste-me, para que eu visse que é aquilo que via e que eu, que isso via, ainda não sou." (AGOSTINHO, I998, p.295-297) Esse trecho também possui uma alusão sálmica, dada pelo Salmo 26: "Meu pai e minha mão me abandonaram, / mas Iahweh me acolhe". (AGOSTINHO, 2008) É de suma importância notar que na análise dos versículos anteriores a esse presente no Enarrationes, Agostinho faz novamente uma alusão à luz divina e ao coração. O Bispo diz:

Ouve por que a razão pede: Meu coração te disse: Procurei a tua face. [...] Se nossa alegria dependesse do sol, nosso coração não diria: 'Procurei a tua face, mas diriam nossos olhos corporais. [...] Os olhos carnais voltam-se para a luz visível, os do coração procuram aquela outra luz. Queres ver a luz atingida pelos olhos do coração? Deus é esta luz. [...] Queres, então, ver aquela luz? Purifica os olhos que podem vê-la. (AGOSTINHO I, 2004, p.259 - 260)

Como já dito anteriormente, a razão pede, Deus ilumina. Para que se possa ver essa luz que ilumina é preciso uma purificação dos olhos, uma negação da exterioridade em direção da interioridade para que se possa ver com olhos da mente. Assim, é Deus quem possibilita, por sua misericórdia, a visão dessa luz superior. Nesse excerto do parágrafo dezesseis, aparece novamente algo anunciado anteriormente: Deus é ontologicamente superior. Posteriormente, no decorrer do livro, essa superioridade ontológica de Deus resolve um dos problemas anunciados na introdução deste artigo, isto é, a existência do mal. Isso está enunciado pela confissão de Agostinho de que ele não é. Mas o que significa não ser? Significa que o bispo não é, porque não é aquilo que Deus É. Só Deus É verdadeiramente, e tudo aquilo que é privado do Ser, não é. Desse modo, o mal não é uma substância, pois na medida em que todas as coisas são criadas por Deus, elas são boas, no entanto, por serem privadas do Ser, elas não são e, por isso, são más. Sendo assim, além do mal não ser uma substância corporal, ele não é, também, proveniente de Deus, pois tudo que é, é bom. Portanto, a visão da luz imutável faz Agostinho ver a superioridade dessa luz e a inferioridade ontológica dele em relação a ela. A luz é superior, porque cria. Além disso : "E deslumbraste a fraqueza do meu olhar, brilhando intensamente sobre mim, e estremeci de amor e horror: e descobri que eu estava longe de ti, numa região de dessemelhança" (AGOSTINHO, I998, p.297), o brilho da luz desvela a fraqueza do olhar, porque é pela própria luz que se vê a luz, pois ela mesmo é a condição de possibilidade da visão, sendo assim, ela brilha e faz com que Agostinho a veja. Uma vez vendo-a, ele se deslumbra com esse brilho. Os efeitos desse deslumbramento são dois: amor e horror. Amor, porque essa luz é Deus, é a Verdade que deve ser amada, 
o Bem supremo. Horror, porque a constatação da superioridade divina revela a distância do homem em relação a Deus. Distância essa que - e isso é importante reforçar - não é espacial. A distância nesse caso é uma distância ontológica: Deus É, Agostinho não é. Tal que a alusão a Lucas no fim desse trecho é importantíssima para sua compreensão. No trecho referido por Agostinho do Evangelho de São Lucas, Cristo narra uma parábola intitulada "O Filho Pródigo". Nela, o filho pede a seu pai a parte que lhe cabe de sua herança e emigra para uma região distante, onde esbanja sua fortuna e vive libertinariamente. No entanto, sua fortuna acaba e o filho, necessitado, volta à casa de seu pai e pede que ele o aceite como um humilde empregado. No entanto, o pai festeja a volta do filho e faz uma festa por sua volta, aceitando-o como filho. Na edição da Bíblia do Peregrino há uma nota interessante sobre o versículo aludido por Agostinho nesse trecho que pode ajudar sua compreensão. Ela é dada por: "Distante significa longe da presença paterna, num desterro voluntário, buscando a liberdade. Uma libertinagem que o leva logo à miséria [...] Fome e miséria não são castigo extrínseco, mas consequência de uma conduta, sanção imanente." (AGOSTINHO, 2006, p.2508) Assim, a região de dessemelhança a qual Agostinho alude é a distância não só ontológica por ter sido criado, mas também a distância estabelecida pelo pecado. Se se tiver em mente que o livre-arbítrio será estabelecido como a causa do mal, a parábola do filho pródigo serve como metáfora perfeita à distância nesse trecho. Já havia se estabelecido que o problema do mal é findado na constatação de que Deus É e o homem não é, o destrinchamento dessa constatação levará à não-substancialidade do mal e à concepção do mal como privação de bem. Essa privação se deu, então, porque o homem pecou. Buscando a libertinagem, o homem peca e é levado à miséria, merecendo uma punição. A visão da verdade proporciona, desse modo, três constatações: a superioridade de Deus, a inferioridade do homem e o afastamento ainda maior desse homem inferior através do pecado. Tal que, pelo vocabulário empregado, mesmo que na língua portuguesa, pode-se notar o porquê de uma crítica da espacialidade ser o mote temático do L. VII. Se se tomar superioridade, inferioridade e afastamento em suas acepções espaciais, ter-se-á uma concepção errônea da doutrina cristã, acusando-a de teses que não são as dela. Por isso, a preocupação de Agostinho em depurar seu vocabulário espacial se mostra tão relevante.

Assim, o filósofo prossegue: "como se ouvisse a tua voz vinda do alto: Eu sou o alimento dos adultos: cresce e comer-me-ás. Tu não me mudarás em ti, como o alimento da tua carne, mas tu serás mudado em mim." O verdadeiro alimento é Deus, e não a fome do pecado, da libertinagem, que nunca sacia. Quando se vê Deus e ama-o, ele não muda, pois é imutável, quem muda é o 
homem, que se converte e é colocado no caminho de volta ao Senhor. Nesse trecho, há uma alusão a Jeremias 3I:I5 que merece ser citada:

Assim disse Iahweh / Em Ramá se ouve uma voz, / lamentação, choro amargo; / Raquel chora seus filhos, ela não quer ser consolada por seus filhos, / porque já não existem. / Assim disse Iahweh: / Reprime o teu pranto / e as lágrimas dos teus olhos! / Porque existe recompensa para a tua dor; / - oráculo de Iahweh - / teus filhos voltarão para o seu território. / Escutai os gemidos de Efraim: / 'Tu me corrigiste, eu fui corrigido, / como novilho indômito. / Faze-me voltar e voltarei, / porque tu és Iahweh, meu Deus! / Porque depois de me afastar, me arrependi, / depois que compreendi, bati no peito. (AGOSTINHO, 2008, p.I03)

Como no trecho acima de Jeremias, Agostinho será corrigido por conta de seu pecado se abandonar os alimentos carnais e aceitar Deus como verdadeiro alimento. Essa correção é uma volta ao estado pré-afastamento, ou seja, ao estado anterior ao pecado original. Se essa correção é uma volta, pode-se dizer que a admoestação que faz o bispo se voltar para seu íntimo já é uma etapa dessa correção. Portanto, Deus age na vida do filósofo em todos os momentos, a ação da graça de Deus está presente fazendo com que ele se volte para si mesmo para voltar a Deus. Toda a possibilidade da volta só existe, porque Deus quer. Portanto, todas as etapas até aqui apresentadas só aconteceram, porque Deus quer primeiro.

A confissão continua: "E reconheci que por causa da iniquidade corrigiste o homem e fizeste consumir-se a minha alma como uma aranha," (AGOSTINHO, I998, p.297) Essa passagem alude ao Salmo 38 e, nas Enarrationes (AGOSTINHO, 2004, p.627-63I), Agostinho a comenta dizendo que a correção de Deus é graça. Se a correção de Deus enfraquece o homem, essa fraqueza o coloca em uma posição de humildade para que contemple o Criador. A humilhação é castigo, mas também é ação da graça. Sendo assim, se o brilho da luz divina enfraquece o olhar da alma de Agostinho e essa alma se consome como uma aranha - animal débil e fraco -, essa fraqueza coloca o homem na posição de inferioridade da qual ele deve ter conhecimento, tirando-o da condição de soberba. A mesma luz que ilumina é a que pune, buscando corrigir o homem para que ele se volte a ela.

Mas sem ainda entender o que é essa luz plenamente, o bispo diz: "Porventura nada é verdade, já que não está difundida pelo espaço dos lugares, nem finitos nem infinitos?" (AGOSTINHO, I998, p.297) Ora, seria plenamente aceitável refutar argumentação de Agostinho dizendo: pode-se concordar que tal luz imutável e incorpórea exista, mas de que modo as coisas podem ser Verdade se essa luz não é presente? Como as coisas podem ser verdadeiras se essa luz não está 
nas coisas? Ou, se está nas coisas, de que modo ela está? Como o incorpóreo pode estar presente no locorum spatia? Chegou-se, então, ao momento anunciado co mo mote da análise até aqui apreendida. Ainda imerso no raciocínio espacializante, Agostinho se pergunta como as coisas podem ser, já que são corpóreas. Se Deus é criador e dá o ser às coisas, como ele pode estar presente nas coisas corpóreas, sendo ele incorpóreo? Como Deus pode estar presente no espaço se todo o esforço feito até aqui foi de afastamento da espacialização? A magnitude desse problema é, por assim dizer, sem tamanho. O homem é tão miserável que mesmo com todo o esforço empreendido e a visão da Verdade, ele não consegue fazer o caminho inverso. Se se saiu da exterioridade para a interioridade e, uma vez nesta, viu-se a luz divina, agora o filósofo tem que mostrar como essa mesma luz divina se relaciona com o espaço local cujo esforço de depuração foi tão cansativo. Deus não é corporal e não está no espaço, mas as coisas corporais e espaciais têm seu ser mantido por esse mesmo Deus².

Desse modo, prossegue o texto: "E tu clamaste de longe: Pelo contrário, eu sou o que sou." (Ibid.) Nesse trecho, há mais uma alusão à parábola do filho pródigo, tal que o Pai (Deus) chama o filho pecador para que volte a ele. Qual é esse chamamento? Ele se trata da auto-nominação divina, uma das passagens mais célebres e discutidas do livro do Êxodo. Não será arrogada, neste pequeno trabalho, a pretensão de explicá-la por completo. No entanto, algumas considerações podem ser feitas, seguindo uma estratégia simplória que não comprometa a complexidade do assunto. Deus ser o que é significa que ele é plenamente, é inefável. Além disso, ela pode significar também, segundo a nota correspondente à passagem da Bíblia do Peregrino, aquele que dá o ser, que faz existir. Assim, para que Agostinho não se torne complacente ao fracasso da análise da espacialidade que exige a explicação de como Deus se relaciona com as criaturas, Deus diz que Ele dá o ser. Dito isso, Agostinho ouve: "E ouvi, tal como se ouve no coração, e já não havia absolutamente nenhuma razão para duvidar, e mais facilmente duvidaria de que vivo do que da existência da verdade, a qual se apreende e entende nas coisas que foram criadas." (Ibid.) Deus fala e o coração do bispo ouve, sua razão ouve que Deus é o Criador inefável. A Verdade existe e está inscrita nas coisas, como dito na alusão à Epístola aos Romanos, porque é Deus que dá o ser a elas.

No entanto, o problema da relação de Deus, que é incorpóreo e não está

2 É interessante notar que semelhante dificuldade será encontrada no L. XI das Confissões, pois lá o filósofo fará um esforço para separar a eternidade da temporalidade, mas depois encontrará o impasse de explicar como essa mesma eternidade se relaciona com aquilo que é temporal. 
no locorum spatia, não foi resolvido. Deus diz que é o que é, Agostinho ouve e não tem razão para duvidar, mas a explicação do que Deus é ainda não é dada. Deus não é corpóreo, não está no espaço local, mas o que ele é? Eternidade. O que é a eternidade? O esforço para entendê-la não é dado nesse momento das Confissões. Agostinho vê a luz da Verdade, seu esforço visionário é atingido e um progresso é conseguido: pode-se refutar as teses maniquéias de Deus corpóreo e o mal como substância, mas essa visão êxtásica atingida ainda culmina em um fracasso. A relação de Deus com os seres exige a explicação do que Deus é.

Antes de se concluir tal estudo, é importante fazer uma pequena retrospectiva. Primeiramente constatou-se que a iluminação divina admoesta Agostinho para o caminho da interiorização em detrimento da exterioridade. Posteriormente, argumentou-se que essa interiorização gerada por essa luz III prmite que se veja essa mesma luminosidade. Para vê-la, é necessário que se faça com algo corpóreo. Uma vez vista, essa luz revela a inferioridade ontológica do homem e o afastamento através da queda, colocando-o numa condição miserável de punição. Punição essa que é também graça divina, pois as tribulações operam para que o homem veja sua miséria e se volte a Deus. No entanto, mesmo que o homem volte a essa luz, ele ainda está numa posição de inferioridade, por isso, não consegue entendê-la plenamente. Nessa dificuldade de entendimento de Deus, duas asserções negativas são retiradas: Deus não é corpóreo e não está no espaço. No entanto, o mesmo Deus que pune, é o Deus da misericórdia que age pela graça, Deus que cria, que dá ser. Chega-se ao fracasso do fim do parágrafo dezesseis, separa-se Deus do locorum spatia, mas não se consegue explicar como esse mesmo Deus age no locorum spatia.

Espera-se ter, com o caminho percorrido, explicitado algumas noções centrais do parágrafo dezesseis e a relevância das mesmas para obra agostiniana. Momento central do L. VII, esse trecho também se mostra bastante importante no projeto geral das Confissóes. Pré-anunciado pelos problemas colocados nos livros anteriores, constatador de um fracasso e prenunciante de uma outra depuração a ser feita no L. XI, acredita-se que esse excerto da obra agostiniana é de suma importância para a mesma.

Exterioridade e interioridade, crítica de noções espacializantes, relação de Deus com as criaturas. Tais são noções que podem ser lidas na chave da expressão locorum spatia que se tentou privilegiar na análise do parágrafo. Sair da exterioridade, do espaço local, para o interior de si e, no interior de si, depurar a 
visão intelectual para que a mente veja sem remeter às imagens dos espaços locais, vendo assim a Verdade e constatar que ela está fora do locorum spatia, mas é a criadora dos seres que estão nele e, portanto, relaciona-se com esses seres e age nele: tal foi o que se tentou demonstrar neste artigo.

\section{Referências Bibliográficas:}

AgOStinHO, Santo, Comentário Aos Salmos. Trad. Monjas Beneditinas - Mosteiro de Maria Mãe De Cristo, Revisão de H. Dalbosco, Ed. Paulus, São Paulo, I998.

. Confissões. Trad. Arnaldo do Espírito Santo, João Beato e Maria Cristina de Castro-Maia de Sousa Pimentel. Imprensa Nacional-Casa Da Moeda, Lisboa, 2004 .

. Bíblia de Jerusalém. Trad. organizada por Anderson, A. F., Gorgulho, G. S. e Storniolo, I. Ed. Paulus, São Paulo, 2008.

. Bíblia do Peregrino. Trad. Ivo Storniolo e José Bortolini. Ed. Paulus, São Paulo, 2006.

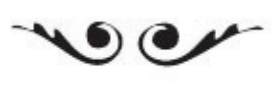

Gléver Cardoso é graduado em Filosofia pela Universidade de São Paulo e em Comunicação Social - Habilitação em Rádio e TV pela Universidade Anhembi Morumbi. Atualmente é mestrando em Filosofia e graduando em Letras - Habilitação em Português/Latim, ambos na Universidade de São Paulo.

E-mail: clevercardoso@gmail.com 